\title{
Candiduria: Epidemiology, Resistance, Classical and Alternative Antifungal Drugs
}

\author{
Aline Raquel Voltan*, Ana Marisa Fusco-Almeida and Maria José Soares Mendes-Giannini \\ Faculty of Pharmaceutical Sciences, UNESP - Univ. Estadual Paulista, Araraquara, São Paulo, Brazil
}

Received: February 22, 2013; Accepted: February 22, 2013; Published: April 25, 2014

*Corresponding author: Aline Raquel Voltan, Faculty of Pharmaceutical Sciences, UNESP - Univ. Estadual Paulista, Araraquara, São Paulo, Brazil, 1621, CEP: 14801-901, Tel: +55-16-3301-5723; Fax: +55-16-3301-5715; E-mail: alinevoltan@yahoo.com.br

\begin{abstract}
Candiduria comprises to the isolation of Candida species in urine of symptomatic and asymptomatic patients. Yeasts of the Candida genus can be found in various ecosystems such as soil, food, water, part of the microbiota of humans and animals. Candida albicans, the opportunistic pathogen, is one of the leading causes of fungal infections in humans, especially in immunocompromised patients. It is a major human fungal pathogen and one of the most common causes of nosocomial urinary tract infection. However, we should emphasize the relevance of non-albicans species that are considered emergent species. Currently, non-Candida albicans species have become a major problem in the hospital environment due to high resistance to antifungal agents available in market. The objective of this review is to demonstrate the prevalence of non-albicans species in urine of hospitalized patients and their characteristics regarding their resistance to classical antifungal agents available in market and alternative drugs that are emerging. The classic antifungals used to treat fungal diseases are the azoles, echinocandins, polyenes and fluocytosine, however, due to the presence of resistance mechanisms to each class of antifungal becomes necessary to find alternatives to treat these infections. Natural products may be a traditional medication and now these days in great demand, as they are perceived to have minimal side effect on humans. As example, pure polyphenol curcumin I (CUR-I) in combination with azoles and polyenes represent a novel therapeutic strategy to improve the activity of common antifungals. Additionally, routine use of a mixture of probiotics may be a useful strategy to reduce the prevalence of candidemia and candiduria. Cranberry juice-derived proanthocyanidins (PACs) features has an excellent in vitro activity against $C$. albicans biofilm formation, among others. Furthermore, the outlook of antifungal resistance in the hospital environment is very worrying, and many researchers have tirelessly sought other alternatives for the treatment of fungal infections.
\end{abstract}

Keywords: Candiduria; Resistance; Species non-albicans

\section{Introduction}

Candiduria refers to the isolation of Candida species in urine of symptomatic and asymptomatic patients [1]. Yeasts of the Candida genus can be found in various ecosystems such as soil, food, water, part of the microbiota of humans and animals. The commensal microorganisms that inhabit the gastrointestinal tract primarily take also part of the vaginal microflora, the urethra and lungs [2]. However, if an imbalance in their relationship with the host occurs, these same yeasts can become pathogenic, thus are considered opportunistic. This imbalance may be due to impairment of host defense mechanisms (extremes of age, underlying disease, immunosuppression) or disruption of anatomical barriers (burns, catheters or invasive surgeries) $[3,4]$ using molecular techniques suggested that the molecular profile of yeasts that colonize the host is similar to that found in cases of infection, which can cause candidemia and consequently candiduria.

The finding of Candida spp in urine may mean that the patient has cystitis or pyelonephritis, or more likely, may only reflect colonization of the perineum, indwelling catheters or bladder. Currently, the laboratory diagnostic tests available are neither sensitive nor specific to reliably distinguish infection from colonization [5]. The colonization is usually asymptomatic but adhesion of Candida spp on drainage catheter in the urinary tract can result in high concentration of Candida colonies in urine cultures. Confirmation of candiduria by a second examination of sterile urine after changing the catheter or suprapubic sample are necessary before further investigation and initiation of treatment $[6,7]$. Most patients with candiduria are asymptomatic and there are no associated signs or symptoms [7].

Currently, non-C. albicans species have become a major problem in the hospital environment due to high resistance to antifungal agents employed during treatment. The objective of this review is to demonstrate the prevalence of non-albicans species in urines of hospitalized patients and their characteristics regarding their resistance to classical antifungal agents available in market and alternative drugs that are emerging.

\section{Epidemiology}

Candida albicans, the opportunistic pathogen, is one of the leading causes of fungal infections in humans, especially in immunocompromised patients [8]. It is a major human fungal pathogen and one of the most common causes of nosocomial urinary tract infection [9]. However, we should emphasize the relevance of non-albicans species that are considered emergent species. Candiduria is very common event among patients exposed to risk factors, and up to $20 \%$ of hospitalized patients may have candiduria throughout its hospitalization, particularly 
patients from intensive care unit $[10,11]$. The common risk factors include urinary tract devices, prior surgical procedures, and recent use of antibiotics, advanced age, female sex, Diabetes mellitus, immunosuppressive therapy and prolonged hospital stay [12-15]. Further, C. albicans has been shown to form biofilms in vivo murine model of catheter associated candiduria [16] and biofilms have been observed on infected urinary catheters in humans [17]. It should be noted, the formation of biofilms is also associated with increased drug resistance. Fungal urinary infections occurred more frequently in patients with urinary catheters than in those without urinary catheters $(40 \%$ versus $22 \%$ ) [18].

The general consensus is that candiduria is very common in hospitalized patients [14,18-20]. There is evidence that the incidence is related to the use of antibiotics [21]. The hospital environment also influences the incidence of candiduria, being more common in intensive care units (ICU) and among those in burn units $[20,22]$.

In a study of Candida species isolated from urine of patients hospitalized in the United States, Kauffman et al. (2000) [14] found C. albicans in the first place (52\%) of all yeasts, followed by C. glabrata (16\%), C. tropicalis (8\%), C. parapsilosis (4\%) and C. krusei (1\%). In Turkey, Ozhak-Baysan et al. (2012) [23] showed that $C$. albicans is more prevalent (44\%) of all yeasts, followed by C. tropicalis (20\%), C. glabrata (18\%), C. krusei (6\%), C. famata (5\%), C. parapsilosis (4\%), C. kefyr (2\%) and C. guilliermondii (1\%). In the urine of diabetic patients hospitalized from Ethiopia, the most common species were C.albicans (42.0\%), C. glabrata (34.2\%) and C.tropicalis (15.8\%) [24] (Table 1). It is possible to observe that the most frequent species in the urine of patients is C.albicans, followed by C.tropicalis or C. glabrata.

In Table 2 is observed the distribution of Candida species in different years in Brazil, being the three most prevalent species C.albicans, C.tropicalis and C.glabrata. Despite the prevalence of C.albicans in infections of the urinary tract, the increased of nonalbicans species are presented.

Most microorganisms causing urinary vesical catheter related to infection originates in the gastrointestinal tract of patients. After use of indwelling catheter, over time, there is an increased

Table 1: Etiology of candiduria in some countries.

\begin{tabular}{|l|c|c|c|}
\hline \multirow{2}{*}{$\begin{array}{l}\text { Etiological } \\
\text { Agent }\end{array}$} & $\begin{array}{c}\text { Kauffman et al. } \\
\text { [14] }\end{array}$ & $\begin{array}{c}\text { Ozhak-Baysan et } \\
\text { al. [23] }\end{array}$ & $\begin{array}{c}\text { Yisman et al. } \\
\text { [24] }\end{array}$ \\
\cline { 2 - 4 } C. albicans & U.S. & Turkey & Ethiopia \\
\hline C. tropicalis & $52 \%$ & $44 \%$ & $42 \%$ \\
\hline C. glabrata & $8 \%$ & $20 \%$ & $15,8 \%$ \\
\hline C. parapsilosis & $4 \%$ & $18 \%$ & $34,2 \%$ \\
\hline C. kefyr & ---- & $4 \%$ & ----- \\
\hline C. famata & ---- & $2 \%$ & ---- \\
\hline C. krusei & $1 \%$ & $5 \%$ & ----- \\
\hline C. & ---- & $6 \%$ & ----- \\
\hline guilliermondii & & $1 \%$ & ----- \\
\hline
\end{tabular}

Table 2: Etiology of candiduriain Brazil.

\begin{tabular}{|l|c|c|c|c|}
\hline $\begin{array}{l}\text { Agente } \\
\text { Etiológico }\end{array}$ & $\begin{array}{c}\text { Kobayashi } \\
{[\mathbf{1 2}]}\end{array}$ & $\begin{array}{c}\text { Passos } \\
{[\mathbf{2 5}]}\end{array}$ & $\begin{array}{c}\text { Binelli } \\
{[\mathbf{2 6}]}\end{array}$ & $\begin{array}{c}\text { Almeida et al. } \\
{[\mathbf{2 7}]}\end{array}$ \\
\hline C. albicans & $35,5 \%$ & $70 \%$ & $52,2 \%$ & $36 \%$ \\
\hline C. tropicalis & $22,2 \%$ & $2 \%$ & $43,5 \%$ & $42 \%$ \\
\hline C. glabrata & $8,8 \%$ & $7 \%$ & ----- & $20 \%$ \\
\hline C. parapsilosis & $11,1 \%$ & $4,6 \%$ & ----- & ----- \\
\hline C. kefyr & ----- & $4,6 \%$ & ----- & ----- \\
\hline C. famata & ----- & $7 \%$ & ----- & ----- \\
\hline C. krusei & $6,6 \%$ & $2,2 \%$ & ---- & $2 \%$ \\
\hline C. guilliermondii & $4,4 \%$ & ----- & ----- & ----- \\
\hline Candidaspp & $11,1 \%$ & ----- & $4,3 \%$ & ----- \\
\hline
\end{tabular}

In Table 2 is observed the distribution of Candida species in different years in Brazil, being the three most prevalent species C.albicans, C.tropicalis and C.glabrata. Despite the prevalence of C.albicans in infections of the urinary tract, the increased of non-albicans species are presented.

colonization of the periurethral region, particularly in catheter interface/mucosa, and microorganisms make use of the catheter surface to ascend into the bladder. In a smaller portion, these microorganisms can be from the hospital environment biotic or abiotic, acquired through the hands of health professionals who improperly handle the system vesical catheter or even through the infusion of contaminated products [28].

The main problem encountered in patients with candiduria by non-albicans species is the resistance of antifungal drugs. Therefore, many of these species are resistant to antifungal agents and there is the requirement to know the mechanisms of resistance involved, as the alternative therapy for these cases.

\section{Treatment and Classical Antifungal Drugs}

The classic antifungals used to treat fungal diseases are the azoles, echinocandins, polyenes and fluocytosine. The largest family of antifungal drugs is the azole family. Azoles disrupt the cell membrane by inhibiting the activity of the lanosterol 14 - $\beta$-demethylase [29], enzyme involved in the biosynthesis of ergosterol. The azole family includes imidazoles (econazole, miconazole, clotrimazole, and ketoconazole) and triazoles (fluconazole, itraconazole), and the latest agentevoriconazole (second-generation, synthetic triazole derivative of fluconazole) and posaconazole (hydroxylated analogue of itraconazole) $[29,30]$. Echinocandins (caspofungin, micafungin, and anidulafungin) are lipopeptidic antifungal agents that inhibit the synthesis of fungal cell wall by noncompetitive blockage of the $(1,3)-\beta$-Dglucan synthase [31]. Polyenes such as nystatin and amphotericin B (both isolated from Streptomyces spp.) bind ergosterol and disrupt the major lipidic component of the fungal cell membrane resulting in the production of aqueous pores [32]. Nucleoside analogues act as inhibitors of DNA/RNA synthesis, flucytosine is a pyrimidine analogue [33].

The presence of yeast in the urine, when viewed under a microscope or culture, should be assessed in the clinical environment, thus is possible to determine their relevance and make the proper decision on the need for antifungal therapy. 
Similar to the case of asymptomatic bacteriuria, there has been a debate about whether it is necessary and how to treat patients with candiduria [34]. Finally, asymptomatic candiduria can be resolved either spontaneously or with the removal of the catheter [35]. High-risk patients can be treated with antifungal prophylactic. In neonatal ICU patients, especially those with low birth weight, fluconazole prophylaxis can prevent invasive candidiasis [36,37]. Concern about the treatment is that the excess of prophylaxis and treatment may affect microbiotome in general [9].

Three major classes of antifungal drugs are currently available for use against Candida infections, but each class has notable limitations, particularly against candiduria [38]. Azole antifungal agents are most commonly used for the treatment of infections with C.albicans but are fungistatic and weakly active against biofilms $[39,40]$. Echinocandins are highly active against C.albicans, but generally do not achieve clinically useful concentrations in the urinary tract [41]. Echinocandins have very few side effects, but are poorly excreted renally [42]. Although there are some studies in animals and humans, there are reports of successful treatment of persistent urinary tract infections with resistant C.glabrata [43,44]. IDSA guidelines, however, do not currently recommend echinocandins for treatment of non-C. albicans candiduria because of very limited clinical data [45]. Amphotericin B has significant toxicities and poor aqueous solubility [46]. Flucytosine, at a dosage of $25 \mathrm{mg} / \mathrm{kg}$ (rounded to the nearest $250 \mathrm{mg}$ ) give by orally four times daily, can also be used to treat cystitis [47]. Due to its suppressive effects of bone marrow, patients have to be monitored. Interest about the emerging development of resistance to treatment with flucytosine may be less relevant for candiduria because of the high concentrations of the drug in urine and relatively short duration of therapy [9]. Fluconazole and caspofungin is excreted primarily in the urine as active forms, being the agents of choice to treat fungal infections of the urinary tract. Unfortunately, some of these antifungal drugs have been used extensively and has led to greater selective pressure and development of antifungal resistance [48].

In neonates, spite of the need for aggressive treatment, few antifungal drugs are specifically indicated for the treatment of invasive Candida. Amphotericin compounds and fluconazole are frequently used, and several newer antifungal agents have become available [45]. All Candida species isolated from the urine of children were susceptible to antifungal agents, except to fluconazole [49]. Almeida et al. [27] demonstrated through antifungal susceptibility testing, that C.albicans was susceptible to both antifungal agents, but $31.2 \%$ of non-C. albicans exhibit eddose-dependent susceptibility to fluconazole, and $3.1 \%$ were resistant to amphotericinB. Intertiary care center in South India, 39 Candida strains were susceptible to amphotericinB, whereas 12 isolates (30.8\%) were resistant to fluconazole [50].

It is important to observe the Candida species in question, since species differ in resistance standard (Table 3).

Several approaches have been proposed to increase the susceptibility of C.albicans to fluconazolin order to deal with failure of treatment, including the combination of different kinds of fluconazol with non-antifungal agents such as antibacterial, calcineurin inhibitors, heat shock protein 90 inhibitors, regulators of calcium homeostasis and traditional Chinese medicine drugs. Many of these combinations showed synergistic effects against C.albicans, in particular resistant strains. The main purpose of this synergism is to increase the membrane permeability, efflux reduce antifungal drugs that interfere with intracellular ion homeostasis, inhibiting the activity of proteins and enzymes necessary for the survival of fungi and inhibit the formation of biofilms [51]. Currently, given the observed yeasts resistance profile, the use of two or more drugs together becomes an alternative treatment to avoid resistance.

\section{Mechanisms of resistance to antifungal}

Microbiological resistance can be primary (intrinsic) or secondary (acquired). Primary resistance is found naturally among certain fungi without prior exposure to the drug and emphasizes the importance of identification of fungal species from clinical specimens. Examples include resistance of C.kruseito fluconazole. Secondary resistance develops among previously susceptible strains after exposure to the antifungal agent and is usually dependent on altered gene expression. The resistance cannot always be predicted, it highlights the importance of individualizing treatment strategies on the basis of the clinical situation [52]. The mechanism of resistance will be different depending on the mode of action of antifungal compounds.

\section{Mechanisms of azole resistance}

The resistance to azoles involves a reduced drug intracellular accumulation, decreased target affinity/processivity for the drug,

Table 3: General patterns of susceptibility of Candida species (modified from Pappas et al.) [45].

\begin{tabular}{|l|c|c|c|c|c|c|c|}
\hline Species & Fluconazole & Itraconazole & Voriconazole & Posaconazole & Flucytosine & Amphotericin B & Candins \\
\hline C. albicans & $\mathrm{S}$ & $\mathrm{S}$ & $\mathrm{S}$ & $\mathrm{S}$ & $\mathrm{S}$ & $\mathrm{S}$ & $\mathrm{S}$ \\
\hline C. tropicalis & $\mathrm{S}$ & $\mathrm{S}$ & $\mathrm{S}$ & $\mathrm{S}$ & $\mathrm{S}$ & $\mathrm{S}$ & $\mathrm{S}$ \\
\hline C. parapsilosis & $\mathrm{S}$ & $\mathrm{S}$ & $\mathrm{S}$ & $\mathrm{S}$ & $\mathrm{S}$ & $\mathrm{S}$ & S to R \\
\hline C. glabrata & $\mathrm{S}$-DD to R & S-DD to R & S-DD to R & S-DD to R & $\mathrm{S}$ & S to I & S \\
\hline C. krusei & $\mathrm{R}$ & S-DD to R & $\mathrm{S}$ & $\mathrm{S}$ & $\mathrm{I}$ to R & S to I & S \\
\hline C. lusitaniae & $\mathrm{S}$ & $\mathrm{S}$ & $\mathrm{S}$ & $\mathrm{S}$ & $\mathrm{S}$ & S to R & S \\
\hline
\end{tabular}

NOTE: I: intermediately susceptible; R: resistant; S: susceptible; S-DD: susceptible dose-dependent.

${ }^{\mathrm{a} E c h i n o c a n d i n}$ resistance among $C$. parapsilosis isolates is uncommon. 
and counteraction of the drug effect. The development of active efflux pumps results in decreased drug concentrations at the site of action. Efflux pumps are encoded in Candida species by 2 gene families of transporters: the $C D R$ genes of the ATP binding cassette super family, and the MDR genes of the major facilitator's class $[53,54]$. Whereas $C D R$ gene up-regulation confers resistance to almost all azoles, $M D R$-encoded efflux pumps have a narrower spectrum specific for fluconazole. It has been demonstrated that mutations in ERG11, the gene encoding for the target enzyme lanosterol C14a-demethylase, prevents binding of azoles to the enzymatic site [55]. Some Candida isolates with reduced susceptibility to azoles have higher intracellular concentrations of ERG11p than azole-susceptible strains [56].

Exposure to azole compounds results in depletion of ergosterol from the fungal membrane and accumulation of the toxic product 14a-methyl-3,6-diol, leading to growth arrest. Mutation of the ERG3 gene prevents the formation of 14a-methyl-3,6-diol from 14a-methylfecosterol [57]. Replacement of ergosterol with the later product leads to functional membranes and contradicts the action of azoles on the ergosterol biosynthetic pathway.

Real-time reverse transcription-PCR quantification showed that sessile cells over expressed ERG11 (coding for lanosterol 14 alpha-demethylase) and MDR1 (coding for an efflux protein belonging to the major facilitator superfamily), thus these mechanisms may contribute to the fluconazole resistance of the C. tropicalis biofilm [58].

\section{Mechanisms of polyene}

Resistance breakpoints for polyenes have not been determined. Most clinicians use a MIC of $\geq 1.0 \mathrm{mg} / \mathrm{ml}$ to indicate resistance to amphotericin B. Defects in the ERG3 gene involved in ergosterol biosynthesis lead to accumulation of other sterols in the fungal membrane. Consequently, polyene-resistant Candida isolate have relatively low ergosterol content, compared with that of polyene-susceptible isolates [59]. Resistance to amphotericin B may also be mediated by increased catalase activity, with decreasing susceptibility to oxidative damage $[60,61]$.

Amphotericin B, the main polyene antimycotic until now is considered as the golden standard for treatment, has antifungal activity against a wide spectrum of species, such as Candida, Aspergillus and Cryptococcus [62]. Amphotericin B has a broad spectrum and the occurrence of resistance is low, the use of amphotericin B is limited due to dose-dependent toxic side effects, such as nephrotoxicity [63].

\section{Mechanisms of echinocandin}

Echinocandins (caspofungin, micafungin, and anidulafungin) are lipopeptidic antifungal agents that inhibit the synthesis of fungal wall by noncompetitive blockage of the $(1,3)-\beta$-Dglucan synthase. The fungicidal activity of the three agents (caspofungin, micafunginandanidulafungin) is concentration dependentagainst most Candida species [64,65].The mechanisms of echinocandin resistance are still being investigated. In Candida species, secondary resistance is associated with point mutations in the Fks1 gene of the $\beta$-1,3-D-glucan synhase complex [66]. Within
Fks1 lies a highly conserved region where several mutations have been identified, mostly at the Ser645 position.

Lagrotteria et al. [67] reported that an echinocandin, a micafungin, is safe and effective drug for the treatment of urinary tract infections. Echinocandins, among antifungal agents, were the most effective against strains of C.glabrata fluconazolesensitive and fluconazole-resistant and micafungin showed the lowest minimum inhibitory concentrations [68].

\section{Mechanisms of flucytosine}

Flucytosine is a pyrimidine base analogue that inhibits cellular synthesis of DNA and RNA. Flucytosine resistance is linked to a deficiency of enzymes involved in the absorption, transport and processing of flucytosine. Genes that encode enzymes involved in the metabolism of flucytosine also contribute to cross-resistance of Candida sp to fluconazole and flucytosine [69]. Some yeast strains are intrinsically resistant to flucytosine impaired because of the absorption cell due to mutations in the gene encoding cytosine permease FCY2 [70,71].

\section{Terapeutic Alternative Antifungals}

Natural products as traditional remedies are in great demand, as they are perceived to have minimal side effect on humans [72]. Various alternatives have been studied with the aim of improving the treatment of infections caused by Candida species.

Some substances has been reported such as maleic acid [73], aqueous extract of Arctium minus, exhibit antifungal effect against Candida species isolated from theoral cavity [74]. Sharma et al. [75] showed the first evidence that pure polyphenol curcumin I (CUR-I) in combination with azoles and polyenes represents a novel therapeutic strategy to improve the activity of common antifungals.

Other alternative are probiotics, for patients receiving broadspectrum antibiotics, routine use of a mixture of probiotics may be a useful strategy to reduce the prevalence of candidemia and candiduria [76].

Kulikov et al. [77] demonstrated that oligo chitosans showed afungistatic activity against Candida species and clinical isolates of C.albicans, which are resistant to a number of classic antifungals. Thus, oligochitos an can be regarded as a possible alternative or addition to the pharmaceutical composition of known antifungal agents.

Cranberry juice-derived proanthocyanidins (PACs) have an excellent in vitro activity against $C$. albicans biofilm formation in artificial urine, preliminary evidence showed that cranberry PAC activity against $C$. albicans biofilm formation is due to antiadherence properties and/or iron chelation [78].

The fungistatic and growth inhibiting effects of Bruceajavanica extract have shown that it has potential to be considered as a promising candidate for the development of antifungal agent in oral health products [79]. Nordinet al. [80] showed that the betel leaf extract has strong fungistatic activity against Candida species. 
Despite the panorama of antifungal resistance in the hospital environment is very worrying, we observed that many researchers have tirelessly sought other alternatives for the treatment of fungal infections.

\section{References}

1. Colombo A, Guimarães T (2007) Candidúria: uma abordagem clínica e terapêutica. Rev Soc Bras Med Trop 40(3): 332-337.

2. Alonso-Valle H, Acha O, Garcia-Palomo JD, Fariñas-Alvarez C, Fernández-Mazarrasa C, et al. (2003) Candidemia in tertiary care hospital: epidemiology and factors influencing motality. Eur J Clin Microbiol Infect Dis 22(4): 254-257.

3. Dignani MC, Solomkin JS, Anaissie E (2003) Candida. In: Anaissie E McGinninis MR, Pfaller MA (Eds.), Med mycology. (1 ${ }^{\text {st }}$ Ed), Churchill Livingstone Philadelphia, US, pp. 195-239.

4. Bonfim-Mendonça Pde S, Fiorini A, Shinobu-Mesquita CS, Baeza LC Fernandez MA, et al. (2013) Molecular Typing of Candida albicans isolates from hospitalized patients. Rev Inst Med trop S Paulo 55(6): 385-391.

5. Bukhary ZA (2008) Candiduria: A Review of Clinical Significance and Management. Saudi J Kidney Dis Transpl 19(3): 350-360.

6. Kauffman CA (2005) Candiduria. Clin Infect Dis 41(6): 371-376.

7. Lundstorm T, Sobel JD (2001) Nosocomial candiduria: A review. Clin Infect Dis 32(11): 1602-1607.

8. Zhang L, Yan K, Zhang Y, Huang R, Bian J, et al. (2007) High through put synergy screening identifies microbial metabolites as combination agents for the treatment of fungal infections. Proc Natl Acad Sci 104(11): 4606-4611

9. Achkar JM, Fries BC (2010) Candida Infections of the Genitourinary Tract. Clin Microbiol Rev 23(2): 253-273.

10. Jarvis WR (1995) Epidemiology of nosocomial fungal infections with emphasis on Candida species. Clinical Infectious Diseases 20(6): 1526-1530.

11. Nucci M (2000) Candiduria in hospitalized patients: a review. Braz J Infect Dis 4(4): 168-172.

12. Kobayashi CC, de Fernandes OF, Miranda KC, de Sousa ED, Silva Mdo R (2004) Candiduria in hospital patients: A study prospective. Mycopathologia 158(1): 49-52.

13. Gubbins PO, McConnell SA, Penzak SR (1999) Current management of funguria. Am J Health Syst Pharm 56(19): 1929-1935.

14. Kauffman CA, Vazquez JA, Sobel JD, Gallis HA, McKinsey DS, et al. (2000) Prospective multicenter surveillance study of funguria in hospitalized patients. Clin Infect Dis 30(1): 14-18.

15. Guler S, Ural O, Findik D, Arslan U (2006) Risk factors for nosocomial candiduria. Saudi Med J 27(11): 1706-1710.

16. Wang X, Fries BC (2011) A murine model for catheter-associated candiduria. J Med Microbiol 60(10): 1523-1529.

17. Maki DG, Tambyah PA (2001) Engineering out the risk for infection with urinary catheters. Emerg Infect Dis 7(2): 342-347.

18. Richards MJ, Edwards JR, Culver DH, Gaynes RP (2000) Nosocomial infections in combined medical-surgical intensive care units in the United States. Infect. Control Hosp Epidemiol 21(8): 510-515.

19. Alvarez-Lerma F, Nolla-Salas J, Leon C, Palomar M, Jorda R, et al. (2003) Candiduria in critically ill patients admitted to intensive care medical units. Intensive Care Med 29(7): 1069-1076.

20. Schaberg DR, Culver DH, Gaynes RP (1991) Major trends in the microbial etiology of nosocomial infection. Am J Med 91(3B): 72S-75S.

21. Weinberger M, Sweet S, Leibovici L, Pitlik SD, Samra Z (2003) Correlation between candiduria and departmental antibiotic use. J Hosp Infect 53(3): 183-186.

22. Bougnoux ME, Kac G, Aegerter P, d'Enfert C, Fagon JY (2008) Candidemia and candiduria in critically ill patients admitted to intensive care units in France: incidence, molecular diversity, management and outcome. Intensive Care Med 34(2): 292-299.

23. Ozhak-Baysan B, Ogunc D, Colak D, Ongut G, Donmez L, et al. (2012) Distribution and antifungal susceptibility of Candida species causing nosocomial candiduria. Med Mycol 50(5): 529-532.

24. Yismaw G, Asrat D, Woldeamanuel Y, Unakal C (2013) Prevalence of candiduria in diabetic patients attending Gondar University Hospital, Gondar, Ethiopia. Iran J Kidney Dis 7(2): 102-107.

25. Passos XS, Sales WS, Maciel PJ, Costa CR, Miranda KC, et al. (2005) Candida colonization in intensive care unit patients' urine. Mem Inst Oswaldo Cruz 100(8): 925-928.

26. Binelli CA, Moretti ML, Assis RS, Sauaia N, Menezes PR, et al. (2006) Investigation of the possible association between nosocomial candiduria and candidaemia. Clinical Microbiology and Infection 12(6): 538-543.

27. Almeida AA, Mesquita CSS Svidzinski TI, Oliveira KM (2013) Antifungal susceptibility and distribution of Candida spp. isolates from the University Hospital in the municipality of Dourados, State of MatoGrosso do Sul, Brazil. Rev Soc Bras Med Trop 46(3): 335-339.

28. Pfaller MA (1996) Nosocomial candidiasis: emerging species, reservoirs and modes of transmission. Clinical Infectious Diseases 22(2): 89-94.

29. Hof H (2006) A new, broad-spectrum azole antifungal: posaconazolemechanisms of action and resistance, spectrum of activity. Mycoses 49(1): 2-6.

30. Hay R (2003) Antifungal drugs. In: Katsambas A \& Lotti T(Eds.), European Handbook of Dermatological Treatments ( $\left.2^{\text {nd }} E d\right)$, Springer, Berlin, Germany, pp: 700-710

31. Grover N (2010) Echinocandins: a ray of hope in antifungal drug Therapy. Indian Journal of Pharmacology 42(1): 9-11.

32. Sanglard D, Odds FC (2002) Resistance of Candida species to antifungal agents: molecular mechanisms and clinical consequences. The Lancet Infectious Diseases 2(2): 73-85.

33. Vermes A, Guchelaar HJ, Dankert J (2000) Flucytosine: a review of its pharmacology, clinical indications, pharmacokinetics, toxicity and drug interactions. Journal of Antimicrobial Chemotherapy 46(2): 171-179.

34. Nicolle LE (2006) Asymptomatic bacteriuria: review and discussion of the IDSA guidelines. Int J Antimicrob Agents 28(1): S42-S48.

35. Sobel JD, Kauffman CA, McKinsey DA, Zervos M, Vazquez JA, et al. (2000) Candiduria: a randomized, double-blind study of treatment with fluconazole and placebo. The National Institute of Allergy and Infectious Diseases (NIAID) Mycoses Study Group. Clin Infect Dis 30(1): 19-24.

36. Healy CM, Baker CJ, Zaccaria E, Campbell JR (2005) Impact of fluconazole prophylaxis on incidence and outcome of invasive candidiasis in a neonatal intensive care unit. J Pediatrics 147(2): 166171. 
37. Healy CM, Campbell JR, Zaccaria E, Baker CJ (2008) Fluconazole prophylaxis in extremely low birth weight neonates reduces invasive candidiasis mortality rates without emergence of fluconazoleresistant Candida species. Pediatrics 121(4): 703-710.

38. Cowen LE, Steinbach WJ (2008) Stress, drugs, and evolution: the role of cellular signaling in fungal drug resistance. Eukaryotic Cell 7(5): $747-764$.

39. Jain N, Kohli R, Cook E, Gialanella P, Chang T, et al. (2007) Biofilm formation by and antifungal susceptibility of Candida isolates from urine. Appl Environ Microbiol 73(6): 1697-1703.

40. Douglas LJ (2003) Candida biofilms and their role in infection. Trends Microbiol 11(1): 30-36.

41. Malani AN, Kauffman CA (2007) Candida urinary tract infections: treatment options. Expert Rev Anti Infect Ther 5(2): 277-284.

42. Boucher HW, Groll AH, Chiou CC, Walsh TJ (2004) Newer systemic antifungal agents: pharmacokinetics, safety and efficacy. Drugs 64(18): 1997-2020.

43. Abruzzo GK, Gill CJ, Flattery AM, Kong AL, Leighton C, et al. (2000) Efficacy of the echinocandin caspofungin against disseminated aspergillosis and candidiasis in cyclophosphamide-induced immunosuppressed mice. Antimicrob Agents Chemother 44(9): 2310-2318.

44. Sobel JD, Bradshaw SK, Lipka CJ, Kartsonis NA (2007) Caspofungin in the treatment of symptomatic candiduria. Clin Infect Dis 44(5): e46e49.

45. Pappas PG, Kauffman CA, Andes D, Benjamin Jr DK, Calandra TF, et al (2009) Clinical practice guidelines for the management of candidiasis: 2009 update by the Infectious Diseases Society of America. Clin Infect Dis 48(5): 503-535.

46. Klepser M (2011) The value of amphotericin B in the treatment of invasive fungal infections. J Crit Care 26(2): 225.e1-10.

47. Tokunaga S, Ohkawa M, Nakashima T, Yamaguchi K, Nishikawa T, et al. (1992) Clinical evaluation of flucytosine in patients with urinary fungal infections. Jpn J Antibiot 45(8): 1060-1064.

48. Espinel-Ingroff A (2009) Novel antifungal agents, targets or therapeutic strategies for the treatment of invasive fungal diseases: a review of the literature (2005-2009). Rev Iberoam Micologia 26 (1): $15-22$.

49. Seifi Z, Azish M, Salehi Z, Zarei Mahmoudabadi A, Shamsizadeh A (2013) Candiduria in children and susceptibility patterns of recovered Candida species to antifungal drugs in Ahvaz. J Nephropathol 2(2): 122-128.

50. Giri S, Kindo AJ, Kalyani J (2013) Candidemia in intensive care unit patients: a one year study from a tertiary care center in SouthIndia. J Postgrad Med 59(3): 190-195.

51. Liu S, Hou Y, Chen X, Gao Y, Li H, et al. (2014) Combination of fluconazole with non-antifungal agents: A promising approach to cope with resistant Candidaalbicans infections and insight into new antifungal agent discovery. Int J Antimicrob Agents S0924-8579(14)00002-8.

52. Kanafani1 ZA, Perfect JR (2008) Resistance to Antifungal Agents: Mechanisms and Clinical Impact. Clin Infect Dis 46(1): 120-128.

53. Albertson GD, Niimi M, Cannon RD, Jenkinson HF (1996) Multiple efflux mechanisms are involved in Candida albicans fluconazole resistance. Anti microb Agents Chemother 40(12): 2835-2841.

54. Sanglard D, Ischer F, Monod M, Bille J (1997) Cloning of Candida albicansgenes conferring resistance to azole antifungal agents: characterization of CDR2, a new multidrug ABC transporter gene. Microbiology 143(2): 405-416.

55. Loffler J, Kelly SL, Hebart H, Schumacher U, Lass-Florl C, et al. (1997) Molecular analysis of cyp51 from fluconazole-resistant Candida albicans strains. FEMS Microbiol Lett 151(2): 263-268.

56. Lopez-Ribot JL, McAtee RK, Lee LN, et al. (1998) Distinct patterns of gene expression associated with development of fluconazole resistance in serial Candida albicans isolates from human immunodeficiency virus infected patients with oropharyngeal candidiasis. Anti microb Agents Chemother 42(11): 2932-2937.

57. Kelly SL, Lamb DC, Kelly DE, et al. (1997) Resistance to fluconazole and cross-resistance to amphotericin B in Candida albicans from AIDS patients caused by defective sterol delta5,6-desaturation. FEBS Lett 400(1): 80-82.

58. Bizerra FC, Nakamura CV, de Poersch C, EstivaletSvidzinski TI, Borsato Quesada RM, et al. (2008) Characteristics of biofilm formation by Candida tropicalis and antifungal resistance. FEMS Yeast Res 8(3): 442-450.

59. Dick JD, Merz WG, Saral R (1980) Incidence of polyene-resistant yeasts recovered from clinical specimens. Antimicrob Agents Chemother 18(1): 158-163.

60. Sokol-Anderson ML, Brajtburg J, Medoff G (1986) Amphotericin Binduced oxidative damage and killing of Candida albicans. J Infect Dis 154(1): 76-83.

61. Mesa-Arango AC, Scorzoni L, Zaragoza O (2012) It only takes one to do many jobs: Amphotericin B as antifungal and immunomodulatory drug. Front Microbiol 3: 286.

62. Ellis D (2002) Amphotericin B: spectrum and resistance. J Anti microb Chemother 49(1): 7-10.

63. Fanos V, Cataldi L (2000) Amphotericin B-induced nephrotoxicity: a review. J Chemother 12(6), 463-470.

64. Cappelletty D, Eiselstein-McKitrick K (2007) The echinocandins. Pharmacotherapy 27(3): 369-388.

65.Vazquez JA (2005) Anidulafungin: a new echinocandin with a novel Profile. Clinical Therapeutics 27(6): 657-673.

66. Balashov SV, Park S, Perlin DS (2006) Assessing resistance to the echinocandin antifungal drug caspofungin in Candida albicans by profiling mutations in FKS1. Anti microb Agents Chemother 50(6): 2058-2063.

67. Lagrotteria D, Rotstein C, Lee CH (2007) Treatment of candiduria with micafungin: A case series. Can J Infect Dis Med Microbiol 18(2): 149150.

68. Mario DAN, Denardi LB, Bandeira LA, Antunes MS, Santurio JM, et al. (2012) The activity of echinocandins, amphotericin B and voriconazoleagainst fluconazole-susceptible and fluconazoleresistant Brazilian Candida glabrata isolates. Mem Inst Oswaldo Cruz 107(3): 433-436.

69. Papon N,Noël T, Florent M, Gibot-Leclerc S,Jean D, Chastin C, et al. (2007) Molecular Mechanism of Flucytosine Resistance in Candida lusitaniae: Contribution of the FCY2, FCY1, and FUR1 Genes to 5-Fluorouracil and Fluconazole Cross-Resistance. Antimicrob Agents Chemother 51(1): 369-371.

70. Peman J, Canton E, Espinel-Ingroff A (2009) Antifungal drug resistance mechanisms. Expert Review of Anti-Infective Therapy 7(4): 453-460. 
71. Espinel-Ingroff A (2008) Mechanisms of resistance to antifungal agents: yeasts and filamentous fungi. Rev Iberoam Micol 25(2): 101106.

72. Maghrani M, Zeggwagh NA, Haloui Met, et al. (2005) Acute diuretic effect of aqueous extract of Retamaraetam in normal rats. J Ethnopharmacol 99(1): 31-35.

73. Mota AC, Lima EO, Castro RD, Batista AU (2010) Antifungal Activity of Maleic Acid against Candida spp Associated with Oral Infections. Pesq Bras Odontoped ClinIntegr 12(3):357-361.

74. Lubian CT, Teixeira JM, Lund RG, Nascente PS, Del Pino FAB, et al (2010) Atividade antifúngica do extrato aquoso de Arctiumminus(Hill) Bernh. (Asteraceae) sobre espécies orais de Candida. Rev Bras Pl Med 12(2): 157-162.

75. Sharma M, Manoharlal R, Negi AS, Prasad R (2010) Synergistic anticandidal activity of pure polyphenol curcumin I in combination with azoles and polyenes generates reactive oxygen species leading to apoptosis. FEMS Yeast Research 10(5): 570-578.

76. Kumar S, Singhi S, Chakrabarti A, Bansal A, Jayashree M (2013)
Probiotic use and prevalence of candidemia and candiduria in a PICU. Pediatr Crit Care Med 14(9): e409-415.

77. Kulikov SN, Lisovskaya SA, Zelenikhin PV, Bezrodnykh EA, Shakirova DR, et al. (2014) Antifungal activity of oligochitosans (short chain chitosans) against some Candida species and clinical isolates of Candida albicans: Molecular weight-activity relationship. Eur J Med Chem 74: 169-178.

78. Rane HS, Bernardo SM, Howell AB, Lee SA (2014) Cranberry-derived proanthocyanidins prevent formation of Candida albicans biofilms in artificial urine through biofilm- and adherence-specific mechanisms. J Antimicrob Chemother 69(2): 428-436.

79. Nordin MA, Wan Harun WH, Abdul Razak F (2013) Antifungal susceptibility and growth inhibitory response of oral Candidaspecies to Bruceajavanica Linn. Extract. BMC Complement Altern Med 13: 342.

80. Nordin MA, Wan Harun WH, Abdul Razak F, Musa MY (2014) Growth inhibitory response and ultrastructural modification of oralassociated candidal reference strains (ATCC) by Piper betle L. extract. Int J Oral Sci 6(1): 15-21. 